\title{
Comparison of corrective and clinical effects between SRS-Schwab grade IV osteotomy combined with the interbody fusion cage and pure grade IV osteotomy in the treatment of old thoracolumbar vertebral osteoporotic fractures with kyphosis
}

\author{
Qinglong Li, Xing Chen, Huagang Shi \\ Department of Spine Surgery, Sichuan Provincial Orthopedic Hospital, Chengdu, China \\ Contributions: (I) Conception and design: Q Li, H Shi; (II) Administrative support: Q Li, H Shi; (III) Provision of study materials or patients: Q Li, X \\ Chen; (IV) Collection and assembly of data: Q Li, X Chen; (V) Data analysis and interpretation: Q Li, X Chen; (VI) Manuscript writing: All authors; \\ (VII) Final approval of manuscript: All authors. \\ Correspondence to: Huagang Shi. Department of Spine Surgery, Sichuan Provincial Orthopedic Hospital, No. 132 West First Loop, Chengdu 610041, \\ China. Email: shilinan@hotmail.com.
}

Backgroundt To compare the corrective and clinical effects between Scoliosis Research Society (SRS)Schwab grade IV osteotomy combined with the interbody fusion cage and pure grade IV osteotomy in the treatment of old thoracolumbar vertebral osteoporotic fractures with kyphosis.

Methods: Twenty-four cases of old thoracolumbar osteoporotic fractures with kyphosis treated by grade IV osteotomy in Sichuan Provincial Orthopedic Hospital from January 2018 to December 2019 were reviewed. Eleven cases were treated with grade IV osteotomy combined with the interbody fusion cage (group A), and 13 cases were treated with grade IV osteotomy alone (group B). Operation time, blood loss, and perioperative conditions of the 2 groups were recorded. After operation and the last follow up, the kyphosis angle (Cobb angle) and sagittal vertical axis (SVA) were measured by whole-spine splicing X-ray; clinical effect was analyzed by visual analog score (VAS) and Oswestry disability index (ODI).

Results: All operations were successful. Operation time was $239.5 \pm 29.0 \mathrm{~min}$ in group A and $179.2 \pm$ $22.7 \mathrm{~min}$ in group $\mathrm{B}(\mathrm{P}<0.05)$. Intraoperative blood loss in group A was $1,560.9 \pm 378.6 \mathrm{~mL}$ and $1,242.3 \pm$ $339.0 \mathrm{~mL}$ in group $\mathrm{B}(\mathrm{P}<0.05)$. Cerebrospinal fluid leakage occurred in 3 cases in group A and 1 case in group $\mathrm{B}(\mathrm{P}<0.05)$. There were 3 cases of transient neurological symptoms in group A and 1 case in group B $(\mathrm{P}<0.05)$. There was no significant difference in Cobb angle and SVA between the 2 groups $(\mathrm{P}>0.05)$. There was no significant difference in ODI and VAS between the 2 groups $(\mathrm{P}>0.05)$. There were no complications, such as spinal cord injury, internal fixation loosening and fracture, or orthopedic loss.

Conclusions: SRS-Schwab grade IV osteotomy combined with the interbody fusion cage and pure grade IV osteotomy can achieve good short-term orthopedic and clinical effects in the treatment of old thoracolumbar osteoporotic fractures with kyphosis. Corrective and clinical effects of the two groups are equivalent, but the operation time of grade IV osteotomy combined with the interbody fusion cage is longer, the amount of intraoperative blood is greater, and the incidence of complications is higher.

Keywords: Kyphosis; Scoliosis Research Society (SRS)-Schwab grade IV osteotomy; interbody fusion cage; old vertebral fracture

Submitted Nov 26, 2021. Accepted for publication Jan 07, 2022.

doi: 10.21037/apm-21-3852

View this article at: https://dx.doi.org/10.21037/apm-21-3852

(c) Annals of Palliative Medicine. All rights reserved. 


\section{Introduction}

Old thoracolumbar fractures with kyphosis are often caused by missed diagnosis in the early stage of vertebral osteoporotic fractures or failure to stay in bed strictly after diagnosis. With an increase in age, osteoporosis worsens, vertebral body height reduces kyphosis worsens, and intractable low back pain occurs. In severe cases, sensory activity disorders of both lower limbs occur, and cauda equina symptoms can develop, affecting patients' quality of life (1). For patients with old thoracolumbar osteoporotic fracture with kyphosis deformity, if the kyphosis Cobb angle is more than $30^{\circ}$, and strict conservative treatment is ineffective for more than 3 months (including the application of non-steroidal anti-inflammatory drugs, antiosteoporosis drugs, etc.), surgical treatment is required, and posterior osteotomy is generally used in the clinical setting. In recent years, Schwab et al. divided the posterior spinal osteotomy system into 6 grades (2), among which Scoliosis Research Society (SRS)-Schwab grade IV osteotomy is a common surgical method for the treatment of kyphosis, and the clinical effect is generally good. For some cases with severe anterior column compression and severe osteoporosis, some doctors use grade IV osteotomy combined with the interbody fusion cage to increase the stability of the anterior column and reduce the possibility of kyphosis caused by anterior column collapse.

In the present study, we reviewed the data of 24 cases of old thoracolumbar osteoporotic fractures with kyphosis treated by grade IV osteotomy at the Spine Department of Sichuan Provincial Orthopedic Hospital from January 2018 to December 2019. We compared the corrective and clinical effects of grade IV osteotomy combined with the interbody fusion cage and pure grade IV osteotomy in the treatment of old thoracolumbar osteoporotic fractures with kyphosis. The innovation of this study is to evaluate whether the placement of interbody fusion cage is necessary for SRS-Schwab grade IV osteotomy in the treatment of old thoracolumbar osteoporotic fractures with kyphosis, so as to provide a basis for clinical decision-making. We present the following article in accordance with the STROBE reporting checklist (available at https://apm.amegroups.com/article/ view/10.21037/apm-21-3852/rc).

\section{Methods}

\section{General information}

We selected 24 cases of old thoracolumbar osteoporotic fractures with kyphosis treated by grade IV osteotomy in Sichuan Provincial Orthopedic Hospital from January 2018 to December 2019. All procedures performed in this study involving human participants were in accordance with the Declaration of Helsinki (as revised in 2013). The study was approved by ethics board of Sichuan Provincial Orthopedic Hospital (No. KY2020-043-01). Individual consent for this retrospective analysis was waived. The number of cases was relatively small. The main reason is that only 24 of the cases met the inclusion conditions during the study period.

The inclusion criteria were as follows: (I) old thoracolumbar fracture (course $>3$ months); (II) severe kyphosis (Cobb angle $>30^{\circ}$ ); (III) age: males $>55$ years old and females $>50$ years old, BMD (bone mineral density) $t$-value $\leq-2.5$; (IV) strict conservative treatment for $>3$ months was ineffective, including the application of nonsteroidal anti-inflammatory drugs and anti-osteoporosis drugs; (V) follow-up time was $>6$ months, and there were complete clinical and imaging data.

The exclusion criteria were as follows: (I) did not meet the diagnostic criteria of old thoracolumbar osteoporotic fracture with kyphosis (course of disease $<3$ months, Cobb angle $<30^{\circ}$, age: males $<55$ years and females $<50$ years, BMD $t$-value $>2.5$ ); (II) no strict conservative treatment or conservative treatment for $<3$ months; (III) nerve damage; and (IV) follow-up time was $<6$ months, and clinical and imaging data were incomplete.

A total of 24 cases of old thoracolumbar osteoporotic fractures with kyphosis were included, including 8 males and 16 females. The age range was $55-72$ years, with an average of 62.8 years; The course of disease was from 6 to 21 months, with an average of 9.2 months. Injured segments were as follows: 2 cases of T10 vertebrae, 5 cases of T11 vertebrae, 7 cases of T12 vertebrae, 6 cases of L1 vertebrae, and 4 cases of L2 vertebrae. All these patients had long-term chronic low back pain, which was unresolved after strict conservative treatment for $>3$ months (including the application of non-steroidal antiinflammatory drugs and anti-osteoporosis drugs), and there was no nerve damage. Eleven cases were treated with grade IV osteotomy combined with the interbody fusion cage (group A), and 13 cases were treated with pure grade IV osteotomy (group B). There was no significant difference between the 2 groups in terms of sex, age, injury segment, bone mineral density value and imaging parameters, visual analog score (VAS), Oswestry disability index (ODI), and time from injury to operation $(\mathrm{P}>0.05)$, which were comparable (Table 1). 
Table 1 Comparison of perioperative related indexes between the 2 groups (mean \pm SD)

\begin{tabular}{|c|c|c|c|c|c|c|c|c|c|c|c|c|c|c|}
\hline Group & $\begin{array}{l}\text { No. } \\
\text { cases }\end{array}$ & $\begin{array}{c}\text { Sex (male/ } \\
\text { female) }\end{array}$ & $\begin{array}{c}\text { Age } \\
\text { (years) }\end{array}$ & \multicolumn{5}{|c|}{ Damaged segment } & BMD (SD) & Cobb angle & SVA (cm) & VAS (points) & ODI & $\begin{array}{l}\text { Time injured } \\
\text { (months) }\end{array}$ \\
\hline A & 11 & $3 / 8$ & $61.7 \pm 6.1$ & 1 & 2 & 3 & 3 & 2 & $-3.4 \pm 0.4$ & $41.4 \pm 6.9$ & $5.8 \pm 2.2$ & $6.6 \pm 1.6$ & $70.8 \pm 17.0$ & $9.5 \pm 5.1$ \\
\hline B & 13 & $5 / 8$ & $63.8 \pm 6.4$ & 1 & 3 & 4 & 3 & 2 & $-3.7 \pm 0.4$ & $41.2 \pm 5.6$ & $6.0 \pm 3.4$ & $5.8 \pm 1.5$ & $63.2 \pm 15.5$ & $9.0 \pm 3.0$ \\
\hline$x / t$ & & 0.336 & -0.797 & & & 0.177 & & & 2.111 & 0.052 & -0.190 & 1.252 & 1.127 & 0.271 \\
\hline
\end{tabular}

BMD, bone mineral density; SD, standard deviation; SVA, sagittal vertical axis; VAS, visual analog scale; ODI, Oswestry disability index.

\section{Surgical method}

After general anesthesia, the patient was placed in the prone position. Disinfected the operating area and laid sterile surgical towel, located the preset osteotomy and fixed segments before operation, conducted the posterior median incision, cut the skin, subcutaneous tissue and deep fascia layer by layer, blunt peeled the paravertebral muscle, and exposed the osteotomy and fixed segments. During the operation, the proximal and distal supraspinous and interspinous ligaments of the operating segments was protected to prevent postoperative borderline kyphosis. Pedicle screws were inserted into the distal and proximal vertebral bodies of the injured vertebral body. If the patient had severe osteoporosis and the screw was obviously unstable, it could be replaced with a bone cement screw, depending on the situation. The spinous process, bilateral lamina, superior and inferior articular processes of the injured vertebra, the lamina below the superior vertebra, and inferior Guan ganglion process were removed, and the bilateral pedicle of the injured vertebra was exposed. One side was temporarily fixed with a short rod, and the contralateral pedicle was removed with a grinding drill to expose the posterior edge of the vertebral body. A bone knife was used to cut off the cortical bone behind the injured vertebra at the middle of the posterior edge of the vertebral body. Cancellous bone was cut out in the upper part of the injured vertebra in a wedge shape, removed the upper intervertebral disc attached to the upper endplate of the injured vertebra, and paid attention to protecting the lower endplate of the injured vertebra and the attached lower intervertebral disc. Scraped off the lower endplate of the upper vertebral body until the bone surface showed spot bleeding. With the same method, the other side of the osteotomy was performed until the anterior vertebral body was penetrated. Pushed the residual posterior superior wall of the vertebral body into the cavity of the vertebral body with posterior edge processor and nucleus pulposus forceps to push, and cleaned up the residual part of the posterior superior wall of the injured vertebral body.

Group A (treated with grade IV osteotomy combined with the interbody fusion cage): The dural sac and nerve root were protected. In the "super intervertebral foramen" area formed after penetrating through the upper and lower intervertebral foramen of one side of the injured vertebra, an appropriate amount of autologous bone and allogeneic bone particles were implanted in the intervertebral space between the residual injured vertebra and the upper vertebra, an intervertebral fusion cage of appropriate size (filled with autologous bone and allogeneic bone), and a shaped connecting rod was placed. Compression forceps were used to close the osteotomy surface and correct kyphosis deformity. If necessary, adjusted the angle of the operating table to assist in reduction. In order to ensure that the "super intervertebral foramen" area was large enough to avoid nerve root compression, the injured vertebral body should be kept at least $1 \mathrm{~cm}$ high. Posterolateral bone grafting, locking internal fixation, routine drainage, and layer-by-layer suture were performed.

Group B (treated with grade IV osteotomy): After osteotomy, an appropriate amount of autologous bone and allogeneic bone particles was implanted in the intervertebral space between the residual injured vertebra and the upper vertebra, the shaped connecting rod was directly placed, the compression forceps were pressed longitudinally on both sides in turn, the upper and lower bone surfaces were closed, posterolateral bone graft fusion was performed, internal fixation was locked, drainage was placed routinely, and suture was performed layer by layer. No interbody fusion cage was placed.

The whole operation was completed under the detection of somatosensory-evoked potential and motor-evoked potential. A total of $500 \mathrm{mg}$ methylprednisolone and $50 \mathrm{mg}$ 
Table 2 Comparison of perioperative-related indexes between the 2 groups (mean \pm SD)

\begin{tabular}{lccccc}
\hline Group & No. cases & Operation time (min) & Bleeding volume $(\mathrm{mL})$ & $\begin{array}{c}\text { Cerebrospinal fluid leakage } \\
\text { (cases) }\end{array}$ & $\begin{array}{c}\text { Transient neurological } \\
\text { symptoms }(\mathrm{cases})\end{array}$ \\
\hline $\mathrm{A}$ & 11 & $239.5 \pm 29.0$ & $1,560.9 \pm 378.6$ & 3 & 3 \\
$\mathrm{~B}$ & 13 & $179.2 \pm 22.7$ & $1,242.3 \pm 339.0$ & 1 & 1 \\
$t$ & & 5.594 & 2.154 & 1.645 & 1.645 \\
$\mathrm{P}$ & $<0.01$ & $<0.01$ & $<0.01$ & $<0.01$ \\
\hline
\end{tabular}

SD, standard deviation.

ranitidine were injected intravenously before osteotomy. Autologous blood transfusion was performed in all cases.

\section{Postoperative treatment}

Cefazolin was routinely used to prevent infection after operation. If there was no cerebrospinal fluid leakage, the incision was given negative pressure drainage. If drainage volume was $<50 \mathrm{~mL}$, the drainage tube was removed and cefazolin stopped. When combined with cerebrospinal fluid leakage, normal pressure drainage was given and the drainage tube was placed for 7 days, during which cefazolin was used to prevent infection. All cases were allowed to walk under the protection of brace after removing the drainage tube for 1 day, and the brace was stopped after 3 months. All patients received routine anti-osteoporosis treatment (calcium, vitamin D, bisphosphate drugs). All patients received functional exercise guidance of lumbar muscles and lower limbs.

\section{Observation indicator}

Operation time, blood loss, and perioperative conditions of the 2 groups were recorded. After operation and the last follow up, the kyphosis angle (Cobb angle) and sagittal vertical axis (SVA) were measured by whole-spine splicing $\mathrm{X}$-ray, and the clinical effect was analyzed by VAS and ODI.

\section{Statistical analysis}

SPSS 19.0 statistical software (IBM, Armonk, NY, USA) was used to process the data. Measurement data conforming to the normal distribution were expressed in mean \pm standard deviation. Two independent sample $t$-tests were used for inter-group comparison, and paired sample $t$-test was used for intragroup comparison. Counting data were expressed in examples, and $\chi^{2}$-test was used. $\mathrm{P}<0.05$ was considered to be statistically significant.

\section{Results}

All operations were successful. Twenty-four patients were followed up for 9-24 months, with an average of 14.6 months. Operation time was $239.5 \pm 29.0 \mathrm{~min}$ in group $\mathrm{A}$ and $179.2 \pm 22.7 \mathrm{~min}$ in group $\mathrm{B}(\mathrm{P}<0.05)$. Intraoperative blood loss in group A was $1,560.9 \pm 378.6 \mathrm{~mL}$ and $1,242.3 \pm 339.0 \mathrm{~mL}$ in group $\mathrm{B}(\mathrm{P}<0.05)$. Cerebrospinal fluid leakage occurred in 3 cases in group $\mathrm{A}$ and 1 case in group $\mathrm{B}(\mathrm{P}<0.05)$. There were 3 cases of transient neurological symptoms in group $\mathrm{A}$ and 1 case in group $\mathrm{B}(\mathrm{P}<0.05)$ (Table 2). There was no significant difference in $\mathrm{Cobb}$ angle and SVA between the 2 groups $(\mathrm{P}>0.05)$. There was no significant difference in ODI and VAS between the 2 groups after operation and the last follow up $(\mathrm{P}>0.05)$ (Table 3). There were no complications, such as spinal cord injury, internal fixation loosening and fracture, or orthopedic loss. Typical cases are shown in Figures 1 and 2.

\section{Discussion}

Osteoporosis is a systemic bone disease characterized by decreased bone mineral content, destruction of bone microstructure, bone fragility, and increased risk of fracture. There are approximately 210 million people with low bone mass in China, and more than 100 million patients with osteoporosis. About $70-80 \%$ fractures among middleaged people and the elderly are caused by osteoporosis. The thoracolumbar spine is the most common site of osteoporotic fractures. Old thoracolumbar fractures with kyphosis are often caused by missed diagnosis in the early stage of vertebral osteoporotic fractures. The reasons are as follows: chronic low back pain is relatively common in middle-aged and elderly people. For patients with low back pain, due to lack of understanding, many doctors 
Table 3 Comparison of kyphosis Cobb angle, SVA, ODI, and VAS between the 2 groups after operation and at the last follow up (mean \pm SD)

\begin{tabular}{|c|c|c|c|c|}
\hline & Group A & Group B & $\mathrm{t}$ value & $P$ value \\
\hline \multicolumn{5}{|l|}{ Cobb Angle } \\
\hline After operation & $5.7 \pm 2.5$ & $6.0 \pm 3.1$ & -0.235 & $>0.05$ \\
\hline Last follow up & $8.3 \pm 1.8$ & $7.6 \pm 3.5$ & 0.553 & $>0.05$ \\
\hline $\mathrm{P}$ & $>0.05$ & $>0.05$ & & \\
\hline \multicolumn{5}{|l|}{ SVA (cm) } \\
\hline After operation & $0.8 \pm 0.4$ & $1.4 \pm 0.7$ & -2.377 & $>0.05$ \\
\hline Last follow up & $1.0 \pm 0.3$ & $1.6 \pm 0.8$ & 0.47 & $>0.05$ \\
\hline \multicolumn{5}{|l|}{ VAS (points) } \\
\hline After operation & $1.1 \pm 0.3$ & $1.0 \pm 0.6$ & 0.47 & $>0.05$ \\
\hline Last follow up & $1.1 \pm 0.5$ & $1.2 \pm 0.7$ & -0.527 & $>0.05$ \\
\hline$t$ & 0 & -1.897 & & \\
\hline $\mathrm{P}$ & $>0.05$ & $>0.05$ & & \\
\hline \multicolumn{5}{|l|}{ ODI } \\
\hline After operation & $16.7 \pm 3.7$ & $17.2 \pm 3.7$ & -0.354 & $>0.05$ \\
\hline Last follow up & $25.9 \pm 8.7$ & $27.1 \pm 10.0$ & -0.301 & $>0.05$ \\
\hline
\end{tabular}

SVA, sagittal vertical axis; ODI, Oswestry disability index; VAS, visual analog scale; SD, standard deviation.

often diagnose "lumbar muscle strain" out of their own experience, resulting in missed diagnosis. Because the patient was not recommended to stay in bed strictly, the height of vertebral body decreased gradually, resulting in kyphosis. Old thoracolumbar fractures with kyphosis are characterized by flexion compression fractures, upper endplate damage, and local angular kyphosis; the apex of kyphosis is located at the posterior upper edge of the injured vertebra. Cases with kyphosis angle $>30^{\circ}$ need surgical treatment $(3,4)$.

Old thoracolumbar osteoporotic fractures are prone to secondary kyphosis, resulting in spinal sagittal imbalance, which will lead to long-term low back pain. They could also cause lower limb or cauda equina symptoms, and seriously affect quality of life (5-8). When the absolute value of the SVA is $>5 \mathrm{~cm}$, the lumbar lordosis decreases or even disappears, which can be considered as sagittal imbalance. Improving sagittal imbalance and correcting kyphosis are important goals of surgical treatment of old thoracolumbar osteoporotic fractures with kyphosis. Smith and other researchers (9) believe that if the postoperative SVA is not effectively corrected, even if the Cobb angle is significantly improved compared with that before operation, it will still seriously affect the quality of life of patients. It is generally believed that posterior osteotomy is an ideal method for the treatment of thoracolumbar osteoporotic fractures with kyphosis. It can minimize the risk of anterior vascular injury, be conducive to the stability of spine and the healing of osteotomy, and obtain satisfactory sagittal imbalance improvement and kyphosis correction effect. However, there is no unified standard for the choice of posterior osteotomy. In 2015, Schwab et al. systematically 

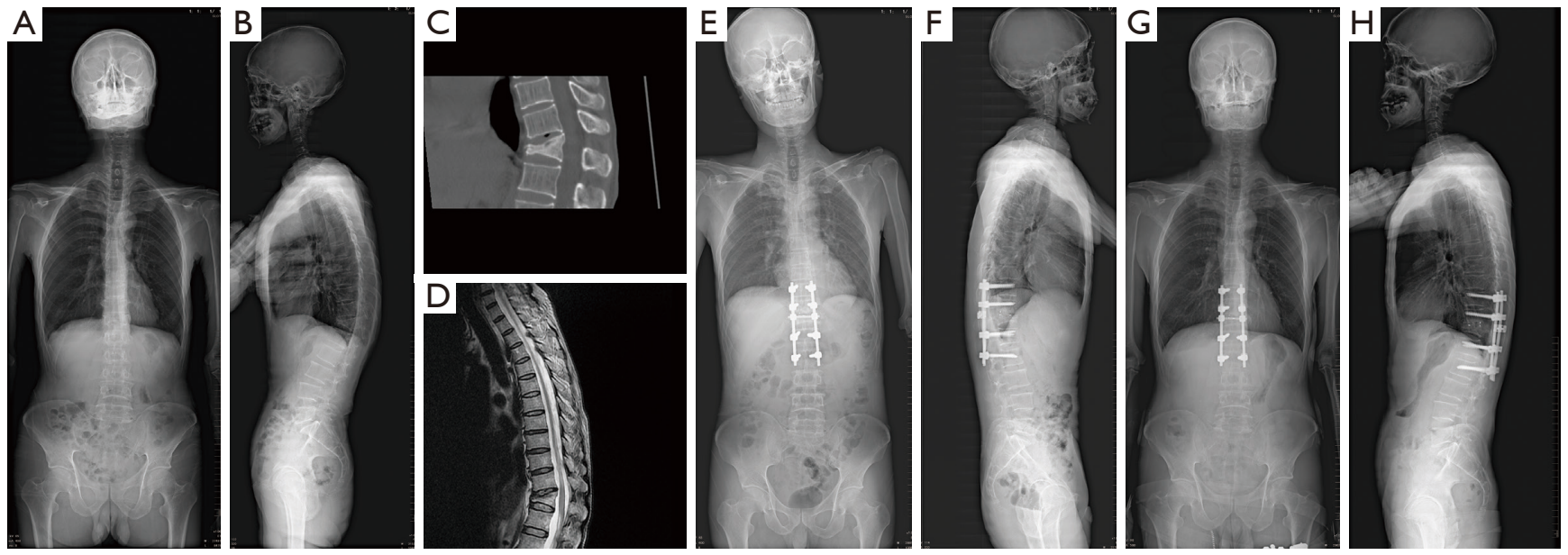

Figure 1 A 60-year-old male with osteoporotic fracture of thoracic 12 vertebral body with kyphosis for 9 months underwent grade IV osteotomy combined with the interbody fusion cage. (A,B) Preoperative whole-spine splicing X-ray showed Cobb angle of $41^{\circ}$ and SVA of $5.2 \mathrm{~cm}$. (C,D) Preoperative computed tomography and magnetic resonance imaging showed old fracture of thoracic 12 vertebral body with kyphosis. (E,F) Cobb angle was $5^{\circ}$ and SVA was $0.6 \mathrm{~cm}$ on the $\mathrm{X}$-ray of the whole spine after operation. $(\mathrm{G}, \mathrm{H}) 12$ months after operation, the whole-spine splicing $\mathrm{X}$-ray showed that the Cobb angle was $8^{\circ}$ and the SVA was $0.9 \mathrm{~cm}$. SVA, sagittal vertical axis.
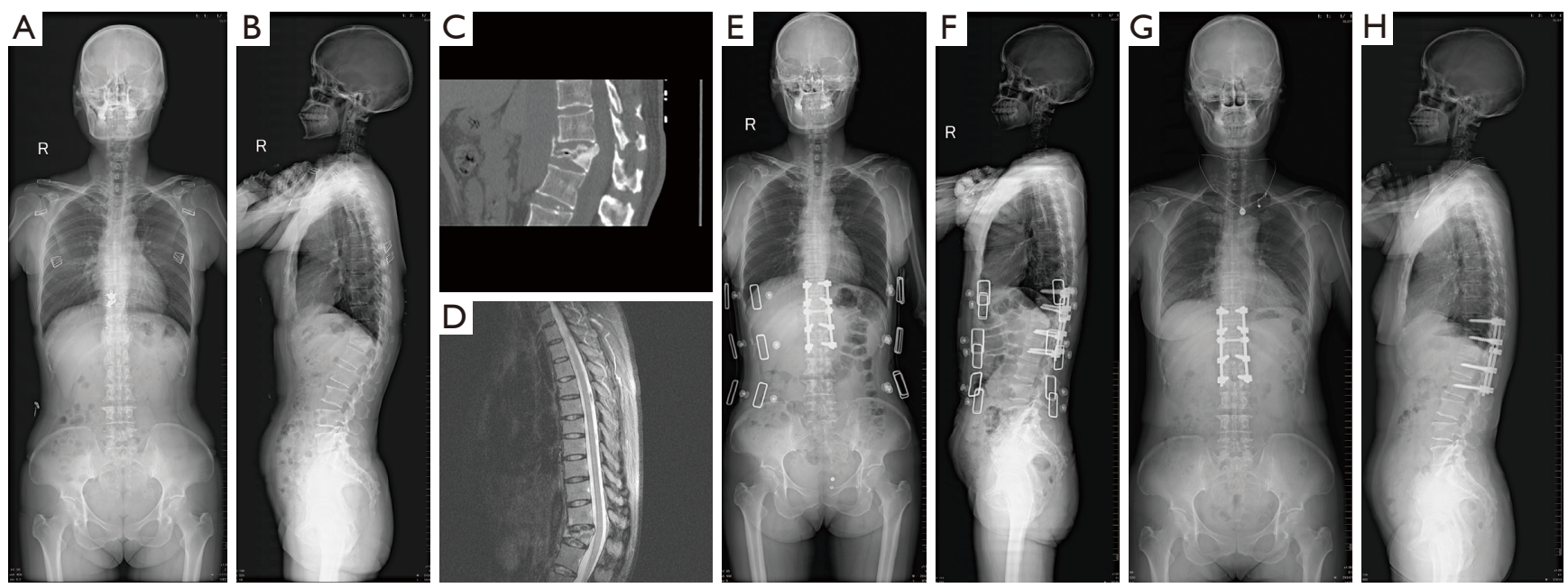

Figure 2 A 53-year-old female patient with osteoporotic fracture of thoracic 12 vertebral body with kyphosis for 11 months underwent pure grade IV osteotomy. (A,B) Preoperative whole-spine splicing X-ray showed Cobb angle of $38^{\circ}$ and SVA of $1.2 \mathrm{~cm}$. (C,D) Preoperative computed tomography and magnetic resonance imaging showed old fracture of thoracic 12 vertebral body with kyphosis. (E,F) Cobb angle was $3^{\circ}$ and SVA was $0.4 \mathrm{~cm}$ on the $\mathrm{X}$-ray of the whole spine after operation. $(\mathrm{G}, \mathrm{H}) 12$ months after operation, the whole-spine splicing $\mathrm{X}$-ray showed that the Cobb angle was $3^{\circ}$ and the SVA was $0.5 \mathrm{~cm}$. SVA, sagittal vertical axis.

proposed 6 grades of osteotomy surgery based on spinal anatomy to standardize and guide the surgical treatment of spinal deformities. Among them, SRS-Schwab grade IV osteotomy is widely used in the surgical treatment of old thoracolumbar fractures with kyphosis, and the clinical effect is satisfactory. For some cases with severe osteoporosis, the amount of bone in the injured vertebrae is less and the anterior column is lack of support, clinically, some doctors use grade IV osteotomy combined with the interbody fusion cage to increase stability and reduce the possibility of loss of corrective effect caused by vertebral body height reduction. Whether the interbody fusion cage 
needs to be placed is controversial in the clinical setting, and relevant comparative research has not been reported in the literature. In the present study, we compared the corrective and clinical effects of grade IV osteotomy combined with interbody fusion cage and pure grade IV osteotomy in the treatment of old thoracolumbar osteoporotic fractures with kyphosis, so as to provide a reference base for the selection of clinical operation methods.

\section{Common surgical methods for the treatment of old thoracolumbar osteoporotic fractures with kyphosis and their advantages and disadvantages}

In recent years, posterior osteotomy has become the first choice for the treatment of thoracolumbar kyphosis. There are many methods of posterior osteotomy, including Smith Petersen osteotomy (SPO), pedicle subtraction osteotomy (PSO), and vertebral column resection (VCR). SPO completes the correction through the $\mathrm{V}$-shaped osteotomy of thoracolumbar attachments and the opening of the anterior column. It has the advantages of simple operation and low operation risk. It is suitable for the correction of kyphosis deformity with support function of the anterior column, and certain range of motion of the intervertebral space. However, the correction angle of SPO is limited at only about $10^{\circ}$. Old thoracolumbar fractures are usually stiff, often complicated with spinal canal stenosis and neurospinal cord compression. SPO cannot perform spinal canal decompression, and it is difficult to achieve a satisfactory orthopedic effect (10). VCR has a good effect, but the operation is difficult, traumatic, and is high risk and has many complications. It is generally used in the correction of severe congenital kyphosis and pathological fracture with deformity. It should be used with caution for elderly patients with osteoporosis. PSO removes the bony structure of the posterior column and part of the vertebral body of the middle column, and then the anterior column is used as the support point to achieve the purpose of orthopedics by shortening the middle and posterior column. The deformity effect of $30-45^{\circ}$ can be obtained by single segmental osteotomy. It has the advantages of small surgical trauma and good orthopedic effect. Therefore, this operation has once become the main operation for the treatment of old thoracolumbar osteoporotic fractures with kyphosis. However, this operation preserves the upper intervertebral disc, which is often damaged in fracture, it is difficult to ensure the bone-to-bone contact between the injured vertebral body and the normal vertebral body. In addition, it is difficult to achieve accurate wedge osteotomy in the injured vertebrae with low anterior column and high posterior column. The injured intervertebral disc could squeeze into the vertebrae, resulting in internal fixation failure or orthopedic loss $(11,12)$.

The most commonly used percutaneous kyphoplasty in the treatment of thoracolumbar osteoporotic vertebral compression fractures can alleviate some low back pain, but the orthopedic effect is extremely limited and cannot meet the requirements of nerve decompression.

\section{Advantages of grade IV osteotomy in the treatment of old thoracolumbar osteoporotic fractures with kyphosis}

SRS-Schwab grade IV osteotomy resected the wedge-shaped upper half of the vertebral body and the intervertebral disc above it through the pedicle. The correction of kyphosis was completed by shortening the middle posterior column. This operation can remove the upper intervertebral disc of the injured vertebra, ensure the bone-to-bone contact between the injured vertebral body and the normal vertebral body, reduce the risk of operation failure caused by the upper intervertebral disc, and improve the fusion rate. When the pedicle of the injured vertebrae is removed, sufficient nerve root canal can be reserved to avoid nerve root entrapment after operation. It can depressurize the posterior spinal canal of the injured vertebral body at the same time, and it is a spinal shortening operation, which relaxes the spinal cord and nerve roots and reduces the risk of nerve injury (13). The clinical effect of SRS-Schwab grade IV osteotomy in old osteoporotic fractures with kyphosis is rarely reported in the literature. Zhang et al. treated 36 patients with old fracture with kyphosis deformity through grade IV osteotomy and followed the patients up for at least 2 years. The postoperative symptoms of all patients were relieved, and the Cobb angle improved from $40.5^{\circ}$ to $4.8^{\circ}$, with an average of $5.8^{\circ}$. No complications, such as internal fixation failure and correction loss, occurred in all patients (14).

\section{Grade IV osteotomy combined with interbody fusion cage and pure grade IV osteotomy}

The difference between grade IV osteotomy combined with interbody fusion cage and pure grade IV osteotomy is that the former places interbody fusion cage after osteotomy and bone grafting in the residual injured vertebra and upper intervertebral space, so as to increase the stability 
of the anterior column and reduce the possibility of loss of orthopedic effect caused by anterior column collapse. In this study, there were no complications, such as spinal cord injury, internal fixation loosening and fracture, or orthopedic loss. The average Cobb angles of the 2 groups were $41.4^{\circ} \pm 6.9^{\circ}$ and $41.2^{\circ} \pm 5.6^{\circ}$, respectively. The average correction rates of postoperative kyphosis were $86.2 \%$ and $85.4 \%$, respectively. The average SVA before operation was $5.8 \pm 2.2 \mathrm{~cm}$ and $6.0 \pm 3.4 \mathrm{~cm}$, respectively. The average SVA after operation was $0.8 \pm 0.4$ and $1.4 \pm 0.7 \mathrm{~cm}$, respectively. The sagittal imbalance was significantly improved compared with that before operation. The recent orthopedic effect was satisfactory. At the last follow up, the VAS scores were $1.1 \pm 0.5$ and $1.0 \pm 0.6$, respectively, and the ODI scores were $25.9 \pm 8.7$ and $27.1 \pm 10.0$, respectively. The orthopedic and clinical effect of both are equivalent, and both can achieve good short-term orthopedic and clinical effect. However, because the combined placement of interbody fusion cage increases the operation steps, the operation time is longer and the intraoperative blood output is greater. The dural sac and nerve root need to be pulled to complete the placement of the interbody fusion cage, it is more likely to cause cerebrospinal fluid leakage or nerve injury. While increasing the cost of consumables, the incidence of corresponding complications is higher. Some doctors believe that for some cases with excessive loss of anterior column compression height and serious osteoporosis, the placement of the interbody fusion cage can increase the stability of anterior column and reduce the possibility of orthopedic loss caused by anterior column collapse. We think that for the treatment of old osteoporotic fracture with kyphosis, on the basis of the above grade IV osteotomy, there is generally no need to place an intervertebral fusion cage. All patients in the above cases had osteoporosis. After the interbody fusion cage was implanted, due to the significant difference in hardness between the interbody fusion cage and the vertebral body, the interbody fusion cage was prone to subsidence in the later stage, affecting the fusion effect. Due to the low number of cases in the 2 groups and the short follow-up time, long-term follow-up observation is needed to further evaluate the long-term orthopedic and clinical effect.

\section{Use of bone cement nails during surgery}

If the patient has severe osteoporosis, the pedicle screw is obviously unstable and difficult to hold during operation, or the screw is loose during osteotomy, it can be replaced with bone cement screw, depending on the situation. After inserting the bone cement nail, there should be a slow injection of an appropriate amount of polymethylmethacrylate along the hollow screw with the push rod to strengthen the nail path and improve the holding force of the screw. Studies have shown that the use of bone cement screws can increase fixation strength by $197 \%$ (15). The intraoperative injection of bone cement should be operated carefully to prevent the leakage of bone cement into the spinal canal and increase the operation risk.

To sum up, SRS-Schwab grade IV osteotomy combined with interbody fusion cage and pure grade IV osteotomy can achieve good short-term orthopedic and clinical effects in the treatment of old thoracolumbar osteoporotic fractures with kyphosis. The corrective effects and clinical effects of the two are equivalent, but the operation time of grade IV osteotomy combined with interbody fusion cage is longer, the amount of intraoperative blood is more, and the incidence of complications is higher. While increasing the cost of consumables, the incidence of corresponding complications is higher. Therefore, for the treatment of old thoracolumbar osteoporotic fractures with kyphosis, pure SRS-Schwab grade IV osteotomy alone is enough, and there is no need to place intervertebral fusion cage.

\section{Acknowledgments}

Funding: This work was supported by Sichuan Provincial Orthopedic Hospital, General Projects (No. 2017-19).

\section{Footnote}

Reporting Checklist: The authors have completed the STROBE reporting checklist. Available at https://apm. amegroups.com/article/view/10.21037/apm-21-3852/rc

Data Sharing Statement: Available at https://apm.amegroups. com/article/view/10.21037/apm-21-3852/dss

Conflicts of Interest: All authors have completed the ICMJE uniform disclosure form (available at https://apm. amegroups.com/article/view/10.21037/apm-21-3852/coif). The authors have no conflicts of interest to declare.

Ethical Statement: The authors are accountable for all aspects of the work in ensuring that questions related to the accuracy or integrity of any part of the work are appropriately investigated and resolved. All procedures 
performed in this study involving human participants were in accordance with the Declaration of Helsinki (as revised in 2013). The study was approved by ethics board of Sichuan Provincial Orthopedic Hospital (No. KY2020-043-01). Individual consent for this retrospective analysis was waived.

Open Access Statement: This is an Open Access article distributed in accordance with the Creative Commons Attribution-NonCommercial-NoDerivs 4.0 International License (CC BY-NC-ND 4.0), which permits the noncommercial replication and distribution of the article with the strict proviso that no changes or edits are made and the original work is properly cited (including links to both the formal publication through the relevant DOI and the license). See: https://creativecommons.org/licenses/by-nc-nd/4.0/.

\section{References}

1. Zeng Y, Chen Z, Sun C, et al. Posterior surgical correction of posttraumatic kyphosis of the thoracolumbar segment. J Spinal Disord Tech 2013;26:37-41.

2. Schwab F, Blondel B, Chay E, et al. The comprehensive anatomical spinal osteotomy classification. Neurosurgery 2015;76 Suppl 1:S33-41; discussion S41.

3. Lenke LG, Sides BA, Koester LA, et al. Vertebral column resection for the treatment of severe spinal deformity. Clin Orthop Relat Res 2010;468:687-99.

4. Xie J, Wang Y, Zhao Z, et al. Posterior vertebral column resection for correction of rigid spinal deformity curves greater than $100^{\circ}$. J Neurosurg Spine 2012;17:540-51.

5. Huang JH, Liu JL, Sun JK, et al. Modified pedicle subtraction osteotomy for thoracolumbar old fracture with kyphosis. Journal of Spinal Surgery 2015;13:16-9.

6. Hu W, Wang B, Run H, et al. Pedicle subtraction osteotomy and disc resection with cage placement in posttraumatic thoracolumbar kyphosis, a retrospective study. J
Orthop Surg Res 2016;11:112.

7. Li S, Li Z, Hua W, et al. Clinical outcome and surgical strategies for late post-traumatic kyphosis after failed thoracolumbar fracture operation: Case report and literature review. Medicine (Baltimore) 2017;96:e8770.

8. Wei Y, Tian W, Zhang GL, et al. Thoracolumbar kyphosis is associated with compressive vertebral fracture in postmenopausal women. Osteoporos Int 2017;28:1925-9.

9. Smith JS, Shaffrey CI, Lafage V, et al. Comparison of best versus worst clinical outcomes for adult spinal deformity surgery: a retrospective review of a prospectively collected, multicenter database with 2-year follow-up. J Neurosurg Spine 2015;23:349-59.

10. Smith-Petersen MN, Larson CB, Aufranc OE. Osteotomy of the spine for correction of flexion deformity in rheumatoid arthritis. Clin Orthop Relat Res 1969;66:6-9.

11. Xi YM, Pan M, Wang ZJ, et al. Correction of posttraumatic thoracolumbar kyphosis using pedicle subtraction osteotomy. Eur J Orthop Surg Traumatol 2013;23 Suppl 1:S59-66.

12. Oner FC, van der Rijt RR, Ramos LM, et al. Changes in the disc space after fractures of the thoracolumbar spine. J Bone Joint Surg Br 1998;80:833-9.

13. Jo DJ, Kim YS, Kim SM, et al. Clinical and radiological outcomes of modified posterior closing wedge osteotomy for the treatment of posttraumatic thoracolumbar kyphosis. J Neurosurg Spine 2015;23:510-7.

14. Zhang X, Zhang X, Zhang Y, et al. Modified posterior closing wedge osteotomy for the treatment of posttraumatic thoracolumbar kyphosis. J Trauma 2011;71:209-16.

15. Leichtle CI, Lorenz A, Rothstock S, et al. Pull-out strength of cemented solid versus fenestrated pedicle screws in osteoporotic vertebrae. Bone Joint Res 2016;5:419-26.

(English Language Editor: R. Scott)
Cite this article as: Li Q, Chen X, Shi H. Comparison of corrective and clinical effects between SRS-Schwab grade IV osteotomy combined with the interbody fusion cage and pure grade IV osteotomy in the treatment of old thoracolumbar vertebral osteoporotic fractures with kyphosis. Ann Palliat Med 2022;11(1):272-280. doi: 10.21037/apm-21-3852 